\title{
In Rotterdam, size really does matter: implications of pulmonary artery enlargement on mortality
}

\author{
Aline N. Zouk ${ }^{1,2}$ and J. Michael Wells $s^{1,2,3}$
}

Affiliations: 'Division of Pulmonary, Allergy, and Critical Care Medicine, University of Alabama at Birmingham (UAB), Birmingham, AL, USA. ${ }^{2} \mathrm{UAB}$ Lung Health Center, Birmingham, AL, USA. ${ }^{3}$ Birmingham VA Medical Center, Birmingham, AL, USA.

Correspondence: J. Michael Wells, 1900 University Blvd, THT 422, Birmingham, AL 35294, USA. E-mail: jmwellsquabmc.edu

@ERSpublications

In a general population, the PA:A is associated with increased mortality in moderate to severe COPD http://ow.ly/L9S130bNuq7

Cite this article as: Zouk AN, Wells JM. In Rotterdam, size really does matter: implications of pulmonary artery enlargement on mortality. Eur Respir J 2017; 49: 1700750 [https://doi.org/10.1183/13993003.007502017].

For quite some time, we have known that pulmonary hypertension $(\mathrm{PH})$ is associated with an increased risk of death in chronic obstructive pulmonary disease (COPD) $[1,2]$. The occurrence of PH in the context of chronic lung diseases is often the result of hypoxic pulmonary hypertension and is classified as Group III $\mathrm{PH}$ by the World Health Organization (WHO) [3]. The diagnosis of PH requires a high index of suspicion, as symptoms are often vague and nonspecific, particularly among individuals with pre-existing respiratory disease. $\mathrm{PH}$ is defined by hemodynamic measurement during right-sided heart catheterisation (RHC), even though RHC is not routinely performed in COPD, because of the invasive nature of the procedure and the lack of efficacious treatments [4-6]. Comorbid PH independently accounts for worsening dyspnoea, fatigue, impaired exercise tolerance and poor quality of life in COPD $[7,8]$, and is associated with increased risk of hospitalisation and higher mortality $[2,3,9]$.

With advances in imaging technologies, many studies have evaluated the utility of various noninvasive surrogate markers for PH. These include echocardiography [10, 11], cardiac magnetic resonance imaging (MRI) [12] and computed tomography (CT) [9, 13-17]. Recently, there has been significant interest in the use of CT in COPD, with several studies evaluating the utility of the ratio of the pulmonary artery to ascending aortic diameter (PA:A ratio) and pulmonary arterial enlargement [15-19]. The PA:A has been calculated in several cohorts of healthy patients and those with different chronic respiratory conditions, and correlates with PA pressures as measured by RHC [9, 15-17, 20-22] and worsening clinical outcomes $[15,17,18,20,21,23-25]$. In a cohort of very severe COPD patients, the PA:A correlated with invasive haemodynamics, and a PA:A $>1$ independently predicted $\mathrm{PH}$ defined as a mean PA pressure $>25 \mathrm{mmHg}$ at right heart catheterisation with a sensitivity of $73 \%$ and a specificity of $84 \%$ [16]. Moreover, its presence was independently associated with an increased risk of severe COPD exacerbations [17] and an increased risk of cardiac injury and in-hospital mortality in individuals hospitalised with COPD exacerbations [18]. The PA:A ratio also predicts increased mortality in patients with advanced lung disease; a PA:A $>1$ was significantly associated with an increased risk of mortality in patients with very severe COPD who were undergoing evaluation for lung transplantation [15]. Similar findings were reiterated in a similar study on idiopathic pulmonary fibrosis (IPF) [20]. The associations between the PA:A and clinical outcomes in

Received: April 102017 | Accepted after revision: April 172017

Conflict of interest: Disclosures can be found alongside this article at erj.ersjournals.com

Copyright @ERS 2017 
TABLE 1 Associations between the ratio of the pulmonary artery to ascending aortic diameter (PA:A ratio) and clinical outcomes

\begin{tabular}{|c|c|c|c|c|}
\hline Study & Population & PA:A value & Outcome & Results \\
\hline \multirow{4}{*}{ WeLLs et al. [17] (2012) } & 2005 nationts with & $P A \cdot A>1$ & $\begin{array}{l}\text { Any AECOPD } \\
\text { Severe AECOPD in } 1 \text { year }\end{array}$ & $\begin{array}{l}\text { OR } 1.86(1.54-2.24)^{*} \\
\text { OR } 28(2.11-3.71)^{*}\end{array}$ \\
\hline & ¿UUS pattents Witn CUPL & PA:A $>1$ & Any AECOPD in 1 year & OR $2.17(1.71-2.74)^{*}$ \\
\hline & & & Severe AECOPD in 3 years & OR $3.81(3.04-4.78)^{*}$ \\
\hline & & & Any AECOPD in 3 years & OR $6.68(4.47-9.96)^{*}$ \\
\hline $\begin{array}{l}\text { BAPTISTA et al. [24] } \\
\text { (2013) }\end{array}$ & 39 patients with acute $\mathrm{PE}$ & PA:A & Mortality & NS \\
\hline SHIN et al. [15] (2014) & 65 patients with advanced COPD & $P A: A>1$ & Transplant-free survival & HR $5.05(1.63-15.6)^{*}$ \\
\hline $\begin{array}{l}\text { KARAKUs et al. [25] } \\
\text { (2015) }\end{array}$ & 159 patients with HFpEF & PA:A & Cardiovascular events & OR 1.068 (1.035-1.103)* \\
\hline WeLLs et al. [18] (2016) & $\begin{array}{l}134 \text { patients hospitalised for } \\
\text { AECOPD }\end{array}$ & $P A: A>1$ & Cardiac injury (troponin $>0.01$ ) & 2-fold elevation in troponin \\
\hline SHIN et al. [20] (2016) & 98 patients with IPF & $P A: A>1$ & Transplant-free survival & HR $3.35(1.54-7.26)^{*}$ \\
\hline
\end{tabular}

COPD: chronic obstructive pulmonary disease; AECOPD: acute exacerbation of chronic obstructive pulmonary disease; PE: pulmonary embolism; NS: nonsignificant; HFpEF: heart failure with preserved ejection fraction; ICU: intensive care unit; CF: cystic fibrosis; IPF: idiopathic pulmonary fibrosis. *: $p<0.05$.

COPD and other diseases are shown in table 1. These studies however, have all been conducted in well-defined research populations or highly selected subgroups. Thus, little is known about the utility of the PA:A in a general population.

In the current issue of The European Respiratory Journal, TERziKHAN et al. [26] explored the association of the PA:A ratio and all-cause mortality in a Dutch general population. This study was conducted using the well-described Rotterdam cohort, a large prospective population-based cohort. It included 2197 participants, of which $222(10.1 \%)$ had COPD. Participants were followed for a median of 8.8 years, with $423(19.3 \%)$ deaths being reported. The mortality rate in the COPD subgroup was two-fold higher than that in the entire population, with cardiovascular events accounting for most of these deaths. The PA diameter in the general population was $26 \pm 3.7 \mathrm{~mm}$, whereas the PA:A was $0.71 \pm 0.10$. These findings are consistent with those from the Framingham Heart Study, in which a PA diameter of $29 \mathrm{~mm}$ was observed in men and $27 \mathrm{~mm}$ in women, and a PA:A ratio of 0.9 was established as normal [19]. The COPD cohort had a mean PA:A of $0.72 \pm 0.10$, similar to the general population. PA enlargement defined as a PA:A $>1$ was only present in 17 subjects $(0.77 \%)$; thus, the authors evaluated the PA:A as a continuous measure. The authors found an association between an elevated PA:A and increased risk of mortality in patients with COPD, but not in the general population. This association was primarily driven by findings in severe COPD. Moreover, in patients with moderate to severe COPD, there was a significantly increased risk of mortality at higher quartiles of the PA:A values, with those at the highest PA:A quartile exhibiting a three-fold risk of mortality compared to those in the lowest quartile. Furthermore, TerziKHAN et al. found a significant association between the PA:A and $\mathrm{PH}$, defined as a pulmonary artery systolic pressure (PASP) $>40 \mathrm{mmHg}$ on echocardiography in both non-COPD and COPD groups.

The increased risk of all-cause mortality observed in individuals with PA enlargement and COPD does not come as much of a surprise. Epidemiological studies focused on idiopathic pulmonary arterial hypertension have reported a low prevalence of the disease in the general population, estimated to be around 5.9 cases per million adults [27]. Therefore, the prevalence of PA abnormalities is also expected to be low. In contrast, the prevalence of $\mathrm{PH}$ in $\mathrm{COPD}$ is thought to be anywhere between $10 \%-85 \%$, depending on the severity of the disease and the methods used for its diagnosis [16]. In addition, 20\%$37 \%$ of patients with COPD have PA abnormalities, with a PA:A $>1[9,16]$. PH occurs more commonly in severe COPD and the development of elevated pulmonary artery pressures is often associated with hypoxia-mediated vascular changes [28]. Although the study by TeRZIKHAN et al. confirmed the associations between the PA:A and metrics suggestive of $\mathrm{PH}$ on echocardiography, it is noteworthy that 
the PA:A ratio and PA enlargement are not absolutely indicative of $\mathrm{PH}$. Mechanisms other than $\mathrm{PH}$, including inflammation, airway remodelling [29] and hyperinflation also contribute to PA:A abnormalities [9]. Likewise, other comorbid conditions, including heart failure, morbid obesity, sleep apnoea, PA aneurysms and pulmonary embolism can affect the PA:A [30].

The study has many strengths, including the large cohort size, the prospective design and the generalisability achieved by including a large population of both healthy and sick individuals in the outpatient clinic setting. This is the first study to examine the PA:A ratio in a general population, rather than a carefully selected cohort such as those undergoing lung transplant evaluation or critically ill patients. However, it does also have several important limitations. First, PH was defined using echocardiographic measurements of PA systolic pressure, which have been shown to lack diagnostic accuracy in patients with hyperinflation and advanced obstructive lung disease [10]. The use of measurements from RHC might have revealed a greater number of patients with elevated pulmonary artery pressures, especially those with mild to moderate COPD. Second, the COPD group only comprised $10 \%$ of the study cohort and among this group, only $10.6 \%(n=22)$ had severe airflow obstruction. Increases in the risk of mortality were only observed in this small subset of the study cohort. These findings are consistent with those reported by SHIN et al. [15] and suggest that the PA:A might have the greatest prognostic utility for mortality in severe COPD. Third, the study did not report acute exacerbations of COPD in the cohort. Exacerbations are an important confounder to consider, given the associations between these events and the PA:A with mortality. Future studies should evaluate effect modifications due to exacerbations and the resulting associations between the PA:A and mortality. Finally, although this cohort is representative of the larger population, one cannot help but notice the relative absence of other comorbid conditions that are associated with $\mathrm{PH}$.

Overall, the study by TeRzIKHAn et al. [26] demonstrates the utility of the PA:A in a cohort of patients with COPD, sampled from a general population. However, it also raises additional questions about our understanding of the PA:A. Would the prevalence of PA enlargement increase if a greater number of patients with conditions associated with $\mathrm{PH}$ were included in the cohort? How do exacerbations influence the associations between PA:A and mortality? Does the PA:A change over time, and if so, do changes influence the risk of mortality? This study reveals just how much we still have to learn about the utility of the PA:A ratio in COPD. Given the enormous public health burden that COPD presents, there is a need to better understand the implications of imaging-based biomarkers like the PA:A for future studies and for clinical practice. This study is an important first step in this process.

\section{References}

1 Chaouat A, Naeije R, Weitzenblum E. Pulmonary hypertension in COPD. Eur Respir J 2008; 32: 1371-1385.

2 Minai OA, Chaouat A, Adnot S. Pulmonary hypertension in COPD: epidemiology, significance, and management: pulmonary vascular disease: the global perspective. Chest 2010; 137: Suppl. 6, 39S-51S.

3 Seeger W, Adir Y, Barberà JA, et al. Pulmonary hypertension in chronic lung diseases. J Am Coll Cardiol 2013; 62: D109-D116.

4 Blanco I, Santos S, Gea J, et al. Sildenafil to improve respiratory rehabilitation outcomes in COPD: a controlled trial. Eur Respir J 2013; 42: 982-992.

5 Rietema H, Holverda S, Bogaard HJ, et al. Sildenafil treatment in COPD does not affect stroke volume or exercise capacity. Eur Respir J 2008; 31: 759-764.

6 Stolz D, Rasch H, Linka A, et al. A randomised, controlled trial of bosentan in severe COPD. Eur Respir J 2008; 32: 619-628.

7 Taichman DB, Shin J, Hud L, et al. Health-related quality of life in patients with pulmonary arterial hypertension. Respir Res 2005; 6: 92.

8 Sun XG, Hansen JE, Oudiz RJ, et al. Exercise pathophysiology in patients with primary pulmonary hypertension. Circulation 2001; 104: 429-435.

9 Wells JM, Dransfield MT. Pathophysiology and clinical implications of pulmonary arterial enlargement in COPD. Int J Chron Obstruct Pulmon Dis 2013; 8: 509-521.

10 Arcasoy SM, Christie JD, Ferrari VA, et al. Echocardiographic assessment of pulmonary hypertension in patients with advanced lung disease. Am J Respir Crit Care Med 2003; 167: 735-740.

11 Fisher MR, Criner GJ, Fishman AP, et al. Estimating pulmonary artery pressures by echocardiography in patients with emphysema. Eur Respir J 2007; 30: 914-921.

12 Kovacs G, Reiter G, Reiter U, et al. The emerging role of magnetic resonance imaging in the diagnosis and management of pulmonary hypertension. Respiration 2008; 76: 458-470.

13 Podolanczuk AJ, Oelsner EC, Barr RG, et al. High attenuation areas on chest computed tomography in community-dwelling adults: the MESA study. Eur Respir J 2016; 48: 1442-1452.

14 Oelsner EC, Lima JA, Kawut SM, et al. Noninvasive tests for the diagnostic evaluation of dyspnea among outpatients: the Multi-Ethnic Study of Atherosclerosis lung study. Am J Med 2015; 128: 171-180 e175.

15 Shin S, King CS, Brown AW, et al. Pulmonary artery size as a predictor of pulmonary hypertension and outcomes in patients with chronic obstructive pulmonary disease. Respir Med 2014; 108: 1626-1632.

16 Iyer AS, Wells JM, Vishin S, et al. CT scan-measured pulmonary artery to aorta ratio and echocardiography for detecting pulmonary hypertension in severe COPD. Chest 2014; 145: 824-832.

17 Wells JM, Washko GR, Han MK, et al. Pulmonary arterial enlargement and acute exacerbations of COPD. $N$ Engl J Med 2012; 367: 913-921. 
18 Wells JM, Morrison JB, Bhatt SP, et al. Pulmonary artery enlargement is associated with cardiac injury during severe exacerbations of COPD. Chest 2016; 149: 1197-1204.

19 Truong QA, Massaro JM, Rogers IS, et al. Reference values for normal pulmonary artery dimensions by noncontrast cardiac computed tomography: the Framingham Heart Study. Circ Cardiovasc Imaging 2012; 5: 147-154.

20 Shin S, King CS, Puri N, et al. Pulmonary artery size as a predictor of outcomes in idiopathic pulmonary fibrosis. Eur Respir J 2016; 47: 1445-1451.

21 Wells JM, Farris RF, Gosdin TA, et al. Pulmonary artery enlargement and cystic fibrosis pulmonary exacerbations: a cohort study. Lancet Respir Med 2016; 4: 636-645.

22 Huitema MP, Spee M, Vorselaars VM, et al. Pulmonary artery diameter to predict pulmonary hypertension in pulmonary sarcoidosis. Eur Respir J 2016; 47: 673-676.

23 Nakanishi R, Rana JS, Shalev A, et al. Mortality risk as a function of the ratio of pulmonary trunk to ascending aorta diameter in patients with suspected coronary artery disease. Am J Cardiol 2013; 111: 1259-1263.

24 Baptista R, Santiago I, Jorge E, et al. One-shot diagnostic and prognostic assessment in intermediate- to high-risk acute pulmonary embolism: the role of multidetector computed tomography. Rev Port Cardiol 2013; 32: 7-13.

25 Karakus G, Kammerlander AA, Aschauer S, et al. Pulmonary artery to aorta ratio for the detection of pulmonary hypertension: cardiovascular magnetic resonance and invasive hemodynamics in heart failure with preserved ejection fraction. J Cardiovasc Magn Reson 2015; 17: 79.

26 Terzikhan N, Bos D, Lahousse L, et al. Pulmonary artery to aorta ratio and risk of all-cause mortality in the general population: the Rotterdam Study. Eur Respir J 2017; 49: 1602168.

27 Task Force for Diagnosis and Treatment of Pulmonary Hypertension of European Society of Cardiology, European Respiratory Society, International Society of Heart and Lung Transplantation, et al. Guidelines for the diagnosis and treatment of pulmonary hypertension. Eur Respir J 2009; 34: 1219-1263.

28 Evans AM, Hardie DG, Peers C, et al. Hypoxic pulmonary vasoconstriction: mechanisms of oxygen-sensing. Curr Opin Anaesthesiol 2011; 24: 13-20.

29 Dournes G, Laurent F, Coste F, et al. Computed tomographic measurement of airway remodeling and emphysema in advanced chronic obstructive pulmonary disease. Correlation with pulmonary hypertension. Am J Respir Crit Care Med 2015; 191: 63-70.

30 Dobrowolski P, Florczak E, Klisiewicz A, et al. Pulmonary artery dilation indicates severe obstructive sleep apnea in patients with resistant hypertension: the Resist-POL Study. Pol Arch Med Wewn 2016; 126: 222-229. 